Since writing the above my friend, Dr. H. O. Reik of Baltimore, sends me the following note:

On Feb. 1, 1898, a lady, aged 30 years, consulted me because of slight subconjunctival hemorrhages of both eyes, which, she said, had recurred a number of times without any known cause. She was otherwise in perfect health. She remembered that during her high-school life she had been subject to somewhat similar attacks, which came whenever she was doing an excessive amount of reading and study. Lately she had been using the microscope very constantly and had also been reading a good deal. These were none of the usual asthenopic symptoms. Vision was perfect, and there was no manifest hypermetropia. The muscle-balance was also good. Examination under homatropin showed the following error:

R. E.-C. $0.50 \mathrm{D}$ ax $90^{\circ}$

L. E.-C. $0.50 \mathrm{D}$ ax $180^{\circ}$

The above glasses were prescribed, and since that time she had no more trouble of the kind.

$I$ find in my record-book the diagnosis "subconjunctival ecchymosis due to refraction error."

It is noteworthy that the error causing the trouble in both the case of Dr. Reik and my own, was a low degree of myopic astigmatism at reversed axes.

$$
\text { Discussion. }
$$

Dr. C. B. WescotT, Chicago-I am sorry we could not have heard the last page of this paper. I have always been a firm believer in the use of mydriatics after the age that they are usually thought of by my brothers and fathers in the profession. Since my visit to Philadelphia, last year, I have been using them in my older patients. I think the oldest was 64 , and I must say the more I use them the more satisfactory I find them. I quite agree with Dr. Gould, that it is fully as important to correct the low degrees of errors of refraction after forty years as before, and $\bar{I}$ am doing it with great delight.

Dr. J. E. Minney, Topeka-I want to emphasize one point the doctor made. I was two years getting proper glasses when my error was very small. Secondly, I believe the blood.vessels of that man's eyes were not normal, and I would suspect that there would probably be in the future some brain lesion, and if it was a case of mine I should warn the patient to be on guard.

Dr. G. C. SAvage, Nashville-The question of why astigmatism should be more troublesome if vertical in one eye and horizontal in the other, has not been fully set forth, so far as I know. I believe the increased trouble experienced by patients of this kind is due to the fact that the visual axes, in order to harmonize images, throw upon the recti muscles the necessity for breaking their regular movements. We all know, as set forth in a paper by Dr. Jackson, that the image is elongated in the direction of the meridian of greatest curvature. If elongated horizontally in one eye and vertically in the other, the superior rectus of one eye rises to one point and that of the other must go a little beyond it; and, so in going from side to side, for there must of necessity be fusion of images of the part looked at. If one axis has to go so far and the other farther, you can see there is at once a disturbance of harmony. $I$ believe that astigmatism against the rule in one eye and according to the rule in the other, is of more importance to patients on this account.

Dr. HaRold Gifford, Omaha-While I started out as a skeptic concerning the correction of so small a degree as one quar. ter dioptre, I want to report that I have obtained a good result in one case, that of a homeopathic physician, by prescribing a one-eighth dioptra glass.

To Protect Animals from Flies.-According to the Journal $d^{\prime}$ Hygiene, flies and insects will not molest an animal if it is emeared lightly every morning with a salve made by boiling a large handful of laurel leaves in a kilogram of lard. Follow the direction of the hairs.

\section{THE GALVANIC CURRENT FOR THE TREATMENT OF PTERYGIUM.}

Presented to the Section on Oplithalmology at the Forty-ninth Annual Meeting of the American Medical Association, held at Denver, Colo., June 7-10, 1898.

BY HORACE M. STARKEY, M.D.

CHICAGO, ILL.

Since electricity has been used in almost every diseased condition of the eye and its appendages, from senile cataract to stricture of the nasal duct, a brief enumeration only of these various uses would consume all the time allowed. This will not be attempted, but attention will be confined to the use of electricity in one condition-pterygium.

Six years ago at the Detroit meeting of this Section, the writer made a brief statement concerning the treatment of pterygium with a weak galvanic current, which he had been employing with apparently good results for about two years, and requested members of the Section to give the method a trial. While he is not aware that that request has met with any response, he has continued to employ the method then outlined, and longer experience has convinced him that it has decided value in suitable cases.

In September, 1889, the writer, who was at the time much interested in the study of electricity, saw a pterygium that it appeared to him at once would be favorably influenced, if not entirely removed, by the galvanic current. The pterygium was small, the apex just commencing to encroach upon the cornea, and was composed of a few large blood-vessels with a minimum amount of connective tissue and thickening of the conjunctiva. The patient was seen but for a few moments and promised to return in a few days for further examination and treatment. He did not, however, return for nearly a year, and in the meantime no other case was seen in which the conditions seemed favorable for the treatment.

June 2, 1890, however, the patient, S. J. F., age 36, machinist, referred by Dr. Creighton, returned, and the proposed treatment having been explained to him, he consented to a trial of it, and the positive pole, a platinum needle, carrying a current of three milliam. peres was used in the method to be described. The current was passed through the pterygium in three lines for one minute at each place, with the inevitable result that the lumen of the enlarged vessels was closed. The patient was to have returned in a few days for observation and further treatment, but noth. ing was seen of him for nearly a year, when he was met upon the street. In answer to inquiry as to why he had not come back, he said that the eye had been entirely cured by the one treatment, and that he had not thought it necessary to return. An inspection showed that the enlarged vessels had disappeared and that there was but a very slight thickening of the sub-mucous tissue remaining. The patient has been seen from time to time as late as 1896 when, notwithstanding several attacks of mild conjunctivitis, the pterygium remained unchanged. For two years now he has passed from observation. This case is given somewhat in detail, and while it is the first case treated in this way, it is the most brilliant in its results.

Since this first case from two to four pterygia have been treated in this manner each year in private practice, nineteen in all, and about the same number in dispensary and hospital work. In every instance the pterygium has been reduced in size, and in most 
cases the growth has been entirely checked; and while in about 50 per cent. of the cases the cure has been radical, in about 20 per cent. the growth has recommenced at a later period, and some form of operation has been necessary. The percentage of recurrences has been less than after excision or other operations commonly employed, and the recurrences have been nearly all in cases that were unsuitable for electrolysis and where some other form of operation should have been adopted.

The cases which seem to be suitable for electrolysis are those with small pterygia, not encroaching much upon the cornea, and particularly those in which there is considerable enlargement of blood-vessels. Experience seems to show what a knowledge of the action of electricity upon the tissues would lead us to expect that commencing pterygia that are as yet too small to be harmful may be entirely checked by two or three treatments so that they remain quiescent indefinitely, A number of cases have also been treated in old and feeble people who evidently had but a short time to live and in whom the dread of operation was very great. In these cases the sight has been improved, irritation allayed and both the patients and their friends have been very grateful for the relief obtained. The way in which the electricity acts upon the tissues is as follows:

1. It congulates the blood in the vessels, thus stopping the blood current and causing the vessels to disappear. 2. It produces a mild adhesive inflammation of the sub-conjunctival tissues, thus forming a firm cicatrix between the conjunctiva and the sclera, so that the gliding of the former over the latter is prevented, and 3, it destroys micro-organisms in the tissues, so that, if the claims advanced by certain investigators that micro-organisms are the cause of this disease should prove to be well founded, this treatment would still be rational.

These effects are all produced by the positive pole when used as the active agent. When the negative pole is used we get solution and absorption of the submucous hyperplasia and of the thickened conjunctiva.

The method of employing the current is as follows: Any source of electricity may be employed, provided it produces a smooth, constant and certain current of sufficient electro-motive force to overcome the resistance of the body, and provided further that it can be so controlled as to deliver a current of from one to five milliamperes. The current should be completely under control and should be accurately measured by a reliable milliamperemeter, which should measure fractions below five milliamperes. The current at the terminals should be tested before each operation. The apparatus being in good order, the eye to be operated upon should be cocainized and a fine platinum needle, connected with the positive pole of the battery, shoula be introduced through the conjunctiva near the apex of the growth, and passed close to the sclera through and beneath the pterygium, and at a

Note.-Doubtless it is well understood by all that it is not the direct action of the electric current that produces these effects. The current decomposes the salts in solution in the tissues into their acid and alkaline constituents, the acide appearing at the positive pole and the alkalies at the negative pole. The acide at the positive pole have a charring, contracting and hardening effect upon the tissues of the body and coagulate albuminous fluids, while the effect of the alkalies at the negative pole is to soften, dissolve and liquify those tis sues. right angle to the direction of the growth. The circuit may now be completed by having the patient press a well wetted sponge connected with the negative pole against the palm. The currents should be turned on till the meter shows that one, two or three milliamperes are passing.

This current should be maintained for one or two minutes. A second puncture should be made in a line parallel with the first and two millimeters distant, and if it is thought desirable a third may be made. The immediate effect seen is the formation of gas, which appears in bubbles upon the surface at the points of entrance and exit of the needle, and which cause some puffiness of the conjunctiva along the line of puncture. Considerable hyperemia of the conjunctiva is occasioned, but large vessels with which the needle comes in contact are more or less collapsed. The pain occasioned is insignificant, and while there is some feeling of irritation and fullness in the eye for a few days, this has not been sufficient in any case to prevent the patient going about his regular duties. The treatment may be repeated in four or five days, or it may be delayed as many weeks, at the convenience of physician and patient.

The advantages of this method are: First, it avoids any loss of tissue; second, it is painless; third, it does not incapacitate the patient; fourth, it stops the progess of pterygia seen in the early stages. With these advantages is coupled the fact that it seems quite as free from recurrences as any other method. It is not advised except as a palliative in broad, fleshy pterygia or in those encroaching much upon the cornea.

Note. - It is well to use a small current at the first application that the irritability of the eye may be noted.

\section{THE VALUE OF FARADISM IN CHOROIDITIS.}

Presented to the Section on Ophthalmology at the Forty-ninth Annual Meeting of the American Medical Association, held at Denver, Colo., June T-10, 1898.

BY ROBERT F. LEMOND, A.M., M.D.

PROFESSOR OF DISEASES OF THE EYE AND EAR, GROSS MEDICAL COLLEGE. DENYER, COLO

The title of my paper is one that would naturally be called somewhat rare among ophthalmologists. I have in the last fow years come in contact with a great many cases of the various kinds of choroiditis, and have studied the pathology of all the cases very closely. The various kinds of choroiditis are more or less akin, that is, in regard to the puzzling problems that they so often present to the oculist, from the fact that choroiditis has been so hard to completely cure. We have choroidal affections, some of the most com. mon of which it might be well to mention, namely: the areolar, atrophic, disseminated, simple, plastic and suppurative. Now it does not matter a great deal about the different names of these troubles, for they differ more than the real conditions of the choroidal layer, from an etiologic standpoint. I have often been very much puzzled to know what has caused this condition of the eye; we so rarely get a history of the case that helps us out, and so frequently we can get no syphilitic history at all, when often that is the real source of the trouble. But I believe that choroiditis results from various conditions. For instance, we have it in extreme cases of myopia, in the various brain tumors that we come in contact with, which we know are conducive to this character of trouble, and 